\title{
Cumulative Stressors and Traumas and Suicide: A Non-Linear Cusp Dynamic Systems Model
}

\author{
Ibrahim Kira1,2*, Brian Barger ${ }^{3}$, Hanaa Shuwiekh4, Justyna Kucharska5, Amthal H. Al-Huwailah ${ }^{6}$ \\ ${ }^{1}$ Center for Cumulative Trauma Studies, Stone Mountain, GA, USA \\ ${ }^{2}$ Center for Stress, Trauma and Resiliency, Georgia State University, Atlanta, GA, USA \\ ${ }^{3}$ Georgia State University, Atlanta, GA, USA \\ ${ }^{4}$ Fayoum University, Fayoum, Egypt \\ ${ }^{5}$ University of Westminster, London, UK \\ ${ }^{6}$ College of Social Sciences, Kuwait University, Kuwait City, Kuwait \\ Email: *kiraaref@aol.com, bbarger1@gsu.edu, hanaashiwk2000@hotmail.com,j.kucharska@westminster.ac.uk, \\ Alhuwailah.77@ku.edu.kw, al_huwailah77@hotmail.com
}

How to cite this paper: Kira, I., Barger, B., Shuwiekh, H., Kucharska, J., \& Al-Huwailah, A. H. (2019). Cumulative Stressors and Traumas and Suicide: A Non-Linear Cusp Dynamic Systems Model. Psychology, 10, 1999-2018.

https://doi.org/10.4236/psych.2019.1015128

Received: October 9, 2019

Accepted: December 7, 2019

Published: December 10, 2019

Copyright $\odot 2019$ by author(s) and Scientific Research Publishing Inc. This work is licensed under the Creative Commons Attribution International License (CC BY 4.0).

http://creativecommons.org/licenses/by/4.0/

(c) (i) Open Access

\begin{abstract}
The unpredictability of suicide is one of the mental health challenges. Based on the threshold model cumulative stressors and traumas interact with a person's characteristics to produce non-linearly suicidality. The current study tests this non-linear relationship using Catastrophe cusp theory. We used cumulative stressors and traumas (CST) as bifurcation control factor and age as asymmetry control factor and suicide as outcome Cusp factor. We utilized three combined previously collected data sets $(\mathrm{N}=967)$ from Western (the $\mathrm{UK}, \mathrm{N}=177$ ) and non-Western countries (Egypt: $\mathrm{N}=490$, and Kuwait: $\mathrm{N}=$ 300). The combined dataset included $22 \%$ adolescents, $40.2 \%$ males. Age ranged from 14 - 75. The measures included cumulative stressors and traumas, interfaith spirituality, religiosity, and identity salience and suicidality. Further, we used measures of interfaith spirituality, religiosity, and identity salience to explore some of the protective factors. We used correlation, curve estimation regression and Cusp catastrophe statistical method to test the hypothesis of the non-linear threshold cusp (sudden shift) model. The explained variance by Cusp catastrophe model non-linear model was highly superior $\left(R^{2}=0.762\right)$ to the linear model $\left(R^{2}=0.045\right)$ in predicting suicidality. Further, results found that interfaith spirituality, religiosity, and identity salience were powerful protective factors from the sudden emergence of suicidality. We discussed the implications of the results to the conceptualization, prevention, and interventions with suicidal behavior.
\end{abstract}

\section{Keywords}

Suicidality, Non-Linear and Cusp Dynamics, Spirituality, Religiosity, Identity Salience 


\section{Introduction}

Suicide is a major public health concern. Globally, it is estimated that over 800,000 people die by suicide each year, making it the second leading cause of death for people aged 15 - 29 years (World Health Organization [WHO], 2017). There is a myriad of multiple risk factors including affective states (e.g., depressed mood), key personality deficits (e.g., low self-esteem and self-efficacy), deficits in problem-solving abilities, interpersonal difficulties (e.g., Joiner, 2005; Van Orden et al., 2010), dispositional, acquired, and practical factors (Klonsky \& May, 2015), motivational-volitional factors (O’Connor \& Kirtley, 2018), and stressors such as traumatic life events (de Wilde, Kienhorst, Diekstra, \& Wolters, 1992; Orbach \& Iohan-Barak, 2009). While the association with different trauma types with suicide rarely systematically evaluated, robust links have been found between interpersonal violence (or personal identity traumas) and suicide during adolescence (Brent, Baugher, Bridge, Chen, \& Chiappetta, 1999), and between childhood sexual abuse and suicidal behavior (for meta-analysis: Devries et al., 2014). Further, attachment organizations related to attachment disruption were found to be associated with suicide (Adam, Sheldon-Keller, \& West, 1996). Additionally, there is evidence that discrimination and oppression are associated with suicide (Clements-Nolle, Marx, \& Katz, 2006). However, the cumulative impact of different stressors and traumas may be the powerful predictor of suicide that has never been evaluated. The comparative strength of the relationships between different trauma types and suicide and the relationship between the cumulative impact of different trauma types have never been adequately examined.

We propose that all investigated factors in the different theories seem to be the product of the interplay between a person's characteristics as a function of his/her age maturity (as control parameters) and the cumulative impact of external and internal stressors and traumas. While the person's characteristics as a function of his/ her age maturity will determine the threshold of internal tolerance to different stressors and traumas, the cumulative effects of different stressors and traumas will define non-linearly the final outcome of suicidal behavior. We propose a dynamic non-linear system perspective to understanding the dynamics of the interplay between cumulative stressors and personal characteristics as a function of his/her age maturity in the outcome of suicidality. In other words, while personal characteristics as a function of his/her age maturity will determine the thresholds of tolerance of the intense stressors before contemplating or taking the decision to commit suicide, the intensity of cumulative stressors will non-linearly determine the behavior change to take this decision and action. Further, systems are sensitive to small changes in trajectories. In particular, discontinuous or sudden small changes in patterns relate to continuous shifts in control parameters are often accompanied by instabilities of the system dynamics (Schiepek et al., 2011).

Further, suicidality and related phenomena exhibit patterns of unpredictability, and the nonlinear dynamics can explain the unpredictability and the seeming 
chaos of suicide phenomena. Suicidality has emergent properties that can be measured through the interaction of the dynamic nonlinear system components and the cumulative impact of stressors. Further, the concept of nonlinear dynamic systems is consistent with the fluid vulnerability theory of suicide (Rudd, 2006), in that it models the fluctuations and ebb and flow of suicide risk over time and over different unique individual characteristics. Studies of cumulative risk found to follow a non-linear path in causing difficulties and distress (Oldfield, Humphrey, \& Hebron, 2015). In this non-linear threshold model of causality (Kira \& Wrobel, 2016), the accumulation of stressors' impact reaches a threshold where the last stressor becomes the "straw that breaks the camel's back" breaching the threshold of distress tolerance. This non-linear threshold model presumes that individuals have different breaking points. Even for people with higher distress tolerance, the added stressor can cause the person to "break". The statistical model used to examine suicide is typically based on a linear regression approach. However, the influence of environmental, behavioral, psychological, or biological factors on suicidality is often complicated and nonlinear. Small and inconsequential changes in predictive factors may lead to abrupt changes in suicidality outcomes. Under these conditions, the linear approach would seriously limit knowing the effects of factors hypothesized to be relevant to these phenomena. These nonparametric regressions do not have the mechanisms to identify and incorporate "cusp jumps," which are the fundamental advantages of the cusp catastrophe models.

The term nonlinearity is understood in different ways by different disciplines, e.g., some define nonlinearity as different disproportionate responses of the system to an external perturbation, i.e., stressors. Others refer to nonlinear dynamics to describe the complex behavior of systems such as chaotic or fuzzy systems. While there are different non-linear statistical models (e.g., quadratic, cubic) that identify different non-linear trajectories, they do not identify if these non-linear trajectories inherent in the relationship between variables or follow a threshold breaking points. However, numerous nonlinear phenomena that exhibit discontinuous jumps in behavior have been modeled with catastrophe theory. Theory and methodology from nonlinear dynamical systems (NDS) may provide considerable advantage to the study of suicide phenomena. Catastrophe cusp theory (Chen \& Chen, 2015; Thom, 1975) is one application of non-linear dynamics that can be used to verify the threshold model and to describe the factors contributing to the development of suicide following the reach of a certain cumulative intensity value of CST. Catastrophe theory allows for the modeling of large, "catastrophic," non-linear changes in behavior that result from small changes in the continuous predictor. This type of catastrophe model is referred to as the "cusp catastrophe" model (Ehlers, 1995; Gilmore, 1993) since a sudden behavioral change is exhibited once a predictor variable crosses the "cusp" threshold. Nonparametric regressions do not have the mechanisms to identify and incorporate "cusp jumps," which are the fundamental advantages of the cusp catastrophe models. The cusp catastrophe model is capable of handling complex 
linear and nonlinear relationships simultaneously using a high order probability density function that has the advantage of being able to incorporate sudden behavioral jumps (Zeeman, 1976). These nonlinear cusp shifts from one state to another can happen upon exposure to cumulative and proliferated external and internal pressures/stressors (Guastello \& Liebovitch, 2009; Kira \& Wroble, 2016; Zeeman, 1976) and the most recent stressor (or chain of stressors) can falsely appear as the direct cause of suicide. Within this dynamic system model, including linear and non-linear causal chains and loops, the relatively recent single or chain of stressors/ traumas can be the event/s that finally triggers a suicidal response and not the actual cause of the suicide.

Catastrophe theory is a branch of bifurcation theory in the study of dynamical systems to study phenomena characterized by sudden shifts in behavior from small changes in circumstances. The most commonly used catastrophe model in health science investigations thus far has been the cusp, which has two control parameters: 1) asymmetry, which has a smooth and linear relationship with the system output, and 2) bifurcation, which induces a threshold effect on system output. The cusp catastrophe model is capable of handling complex linear and nonlinear relationships simultaneously using a high-order probability density function that has the advantage of being able to incorporate sudden behavioral jumps (Zeeman, 1976). Historically, the cusp catastrophe model has been applied to the prediction of health behaviors (Flay, 1978). For suicidality, we propose two control factors to control the outcome response where personal characteristics as a function of his/her age maturity is the asymmetry control factor that controls the outcome changes asymmetrically from one mode to the other mode eventually as it increases, while the stressors and traumas accumulation is the bifurcation control factor that controls the outcome to split and bifurcate from smooth changes to sudden jumps as it increases.

To date, a dynamic systems approach has not yet been used to investigate the propositions of the non-linear cumulative stressors impact on suicidal behavior. Most of the previous studies focused on personal characteristics that lead to suicide, however, the non-linear impact of cumulative stressors rarely been examined. The primary aim of the present study was to examine the cumulative non-linear dynamics that lead to suicide and provide evidence that the non-linear model explains more variance than linear models of suicide. An additional objective was to explore some of the protective factors (i.e., spirituality, religiosity, and identity salience). Cumulative stressors and traumas (CST) has consistently been a powerful linear predictor of the severity and comorbidity of mental health disorders (e.g., Cloitre et al., 2009; Kira et al., 2008, Kira, Fawzi, \& Fawzi, 2013; Kira, Omidy, \& Ashby, 2014; Martin, Cromer, DePrince, \& Freyd, 2013). The impact of CST dynamics is related to various processes including distress tolerance (Leyro, Zvolensky, \& Bernstein, 2010), stress sensitization, the kindling process (Post, Weiss, \& Smith, 1995), and the diathesis-stress model (Stein, Jang, Taylor, Vernon, \& Livesley, 2002). All assumed a stress tolerance and buffer that breaks upon reaching a threshold that may be different from 
person to person. The influence of cumulative and proliferated stressors, chronic and acute, on mental health outcomes is often complicated and nonlinear (Kira, 2010; Kira, 2017; Kira et al., 2018). Relatively small and inconsequential changes in predictive factors (or control parameters) may lead to abrupt changes in behavior.

Related to a person's characteristics (the control parameters) that determine the threshold to suicide are spirituality, religiosity, and identity. There is evidence that spirituality and religiosity are protective factors for suicidality. Spirituality and religion are associated with decreased risk for suicide ideation and attempts (Bonelli \& Koenig, 2013; Dervic et al., 2004; Rasic, Robinson, Bolton, Bienvenu, \& Sareen, 2011; Wu, Wang, \& Jia, 2015), although some studies have failed to find a relationship (Colucci \& Martin, 2008). Further, the role of identity (e.g., ethnic identity) in suicide is relatively unexplored (see also Kira, 2019); however, there is evidence of its importance in suicide (e.g., Walker, Wingate, Obasi, \& Joiner, 2008). Efforts by Aboriginal groups to preserve and promote their culture and identity were found to be associated with dramatic reductions in rates of youth suicide (Chandler, Lalonde, Sokol, Hallett, \& Marcia, 2003). The prevalence of gender identity disorder was associated with high suicidal risk among veterans (Blosnich et al., 2003). In current Paper, we will further explore the role of interfaith spirituality, religiosity and identity salience in suicide prevention.

The goal of the current study is to explore the association between suicide and different trauma types and validate the cusp (threshold) model of the effects of cumulative stressors (chronic and traumatic) on the emergence of suicidal behavior in different age groups and in Western and non-Western participants. In addition, we will explore some of the protective factors of suicidality: interfaith spirituality, religiosity, and identity.

\section{Hypotheses}

Hypothesis 1: Different trauma types will have a different impact on suicide with interpersonal violence (personal identity trauma), the strongest predictive of suicide.

Hypothesis 2: The non-linear models (quadratic and cubic) will explain more variance than the linear models in estimating the association between cumulative stressors and trauma (CST) and Suicide.

Hypothesis 3: Cusp Model will explain a higher variance than the linear model in the association between CST as bifurcation control factor and age as asymmetry control factor and suicide as an outcome cusp factor.

Hypothesis 4: Spirituality, religiosity, and identity salience (commitment) will associate negatively with suicidality.

\section{Method}

\subsection{The Sample}

We combined three previously collected data sets $(\mathrm{N}=967)$ from Western (the 
UK, $\mathrm{N}=177$ ) and non-Western countries (Egypt: $\mathrm{N}=490$, and Kuwait: $\mathrm{N}=$ $300)$ to check the research hypotheses. The combined dataset included $22 \%$ adolescents, 40.2\% males. Age ranged from $14-75$ (Mean $=26.12$, SD $=9.40)$. For marital status $28 \%$ were married, $67.2 \%$ were single, $1.1 \%$ were widowers, $1.4 \%$ were divorced, and $2.2 \%$ had other marital statuses. For work, 58.7\% were students, $24.8 \%$ were employees, $3.3 \%$ professionals and physicians, $2 \%$ retired, $1.9 \%$ workers, $1.3 \%$ merchants, and $8 \%$ other kinds of work. For socio-economic (SES) level, $74.9 \%$ reported to be in the middle, while $19.3 \%$ reported high to very high SES, and $5.8 \%$ reported to be either poor or very poor. For religion, $56 \%$ were Muslims, 30\% Christians, and 14\% with no religious affiliation. The following describes in detail each of the three sub-samples.

The first sub-sample: The Egypt data

Participants and Procedure: The questionnaire was administered to participants starting the first week of October through the first week of December of 2017. The participation was voluntary. Each participant was informed about the general goals of the study and signed informed consent to participate. The questionnaire took 45 - 60 minutes to complete. The study was approved by the IRB of the sponsoring University.

The study was conducted in three Egyptian cities that geographically and culturally represent the different mix in Egyptian society: Fayoum (Middle Egypt) Qena (Upper Egypt), and Giza/Cairo (which is mostly a melting pot of diversities) cities. Three research teams of clinical psychology graduate students collected the data under the direct supervision of their advisors in each cite.

To obtain a diverse sample of participants, a purposive snowball sampling strategy was used. Three research teams of graduate students in clinical psychology (a different team in each city) collected the data under the direct supervision of their advisors. The sample included $\mathrm{N}=490$, with $41.4 \%$ females. Age ranged from 14 to 75, with Age Mean $=26.03, \mathrm{SD}=10.90$, with $20.4 \%$ adolescents. Localities included Fayoum (Middle Egypt) $(\mathrm{N}=184)$, Qena (Upper Egypt) $(\mathrm{N}=210)$, and Giza/Cairo $(\mathrm{N}=96)$, (which is mostly a melting pot of diversities) cities. For religion, 49.6\% were Muslims, and 50.4\% were Christians. It included students (64.5\%), employees (12.9\%), workers (3.1\%), merchants (2.4\%), professionals (3.4\%), and others (13.6\%). It included $28.6 \%$ married, $68.8 \%$ singles, and $2.6 \%$ had other marital statuses. Among participants $3 \%$ reported to be poor or very poor, $21.9 \%$ reported to have either high or very high SES, while $75.1 \%$ reported being in the middle. For education $6.1 \%$ reported to be illiterate, $3.6 \%$ either elementary or intermediate education, $27.3 \%$ high school, $51.8 \%$ were at college and university level, while $11 \%$ at the graduate level.

\section{The second Sample (The Kuwait data)}

Participants and Procedure: The research team consisted of 4 doctoral students with a professor in Psychology as the project leader. The team members have been trained in conducting questionnaires and interviewing. The sample designed was a purposeful quota sample to represent different age groups, stu- 
dents, and community (50\% of students and 50\% community). The questionnaire was administered to college students using group class format, while the community participants were interviewed personally.

Participants $(\mathrm{N}=300)$, included $61 \%$ females. Age ranged between 15 and 50 , (18.7\% from age 15 - 19) $\mathrm{M}=26.37$, and $\mathrm{SD}=8.50$. Among them, $55.3 \%$ were college students, $36.7 \%$ were employees, $1.3 \%$ were professionals, and $3.7 \%$ were others. Among them, 35\% were married, $60.3 \%$ were single, $3 \%$ were divorced, and $1.7 \%$ had other marital statuses. For socioeconomic status, $22.3 \%$ reported to have a high income, $77 \%$ reported to have enough income, $0.07 \%$ reported to be poor, and $0.0 \%$ reported to be very poor. For religion, participants included 99.7\% Muslims, $0.3 \%$ Christians. For education, 4.7 had an elementary school education, $20.6 \%$ had a high school, $72.7 \%$ had an undergraduate degree, and $2 \%$ had a postgraduate degree.

The Third Sample (the UK data)

Participants and Procedure: Participants $(\mathrm{N}=177)$ were recruited using two strategies. The first was by utilizing a crowdsourcing website "prolific.ac", where the participants received $£ 2$ for completing the survey. It was specified in the settings that they have to be students, age range 18 - 40, and nationality, country of birth and current country of residence: UK. Further, the link to the online survey was sent to a student's university organization in London. Participants $(\mathrm{N}=178)$, included $60.7 \%$ females. Age ranged between 18 and 40, $\mathrm{M}=25.89$, and $\mathrm{SD}=5.66$. Among them, $48.9 \%$ were college students, $39.3 \%$ were employees, $6.2 \%$ were professionals, and $5.6 \%$ were others. Among them, $14.6 \%$ were married, $74.2 \%$ were single, $1.7 \%$ were divorced, and $9.6 \%$ had other marital statuses. For socioeconomic status, $7.3 \%$ reported to have a high income, $70.2 \%$ reported to have enough income, $20.8 \%$ reported to be poor, and $1.7 \%$ reported to be very poor. For religion, participants included $24.2 \%$ Christians, $0.6 \%$ Jewish, $4.5 \%$ other religions, while $70.8 \%$ with no religious affiliation. For education, $21.3 \%$ had a high school, $57.3 \%$ had an undergraduate degree, and $21.3 \%$ had a postgraduate degree.

\subsection{Measures}

The Cumulative Trauma Scale CTS-S (short form) is a measure that was constructed based on the development-based trauma framework (DBTF) (e.g., Kira, 2001; Kira, Ashby et al., 2013; Kira, Fawzi, \& Fawzi, 2013; Kira, Lewandowski et al., 2008; Kira et al., 2018; Kira, Lewandowski, Chiodo, \& Ibrahim, 2014). DBTF identifies and measures different dimensions of individual development that may be affected by stressors and traumatic stressors (i.e., attachment, personal, collective and role identities, and interdependence, as well as serious non-acute and chronic stressors). The CTS-S is a 32-item instrument that measures cumulative stressors and traumas in terms of occurrence, frequency, type, and negative and positive appraisals. The scale is intended to be a comprehensive measure of cumulative stressors and traumas exposure. Cumulative non-traumatic stressors included the serious life changes associated with widowed/divorce and re-marrying, as well as the major life changes in forced relo- 
cations (e.g., uprootedness and immigration), and the experience of seemingly small but recurrent or unremitting hassles or chronic stressors. The scale includes, in addition to cumulative non-traumatic stressors (3 items), seven major trauma types (acute stressors): collective identity trauma (3 items), personal identity trauma (6 items), survival trauma (6 items), attachment trauma (2 items), secondary trauma (7 items), achievement traumas ( 2 items) and gender discrimination (2 items). Collective identity trauma includes trauma-related exposure to war and torture and discrimination based on race, ethnicity, or national origin. Personal identity trauma includes trauma related to sexual abuse, rape, incest, and being robbed. Attachment trauma includes abandonment by parents. Survival trauma includes car accidents, life-threatening illnesses, and natural disasters. The achievement or role identity trauma is intended to measure traumatic stressors related to the achievement of life goals like success in school or business. Secondary trauma includes trauma related to having witnessed a traumatic event occurring to another individual or group and affecting social interdependence. Gender discrimination includes gender discrimination by parents (family) and gender discrimination by society and institutions. Gender discrimination items are worded to apply to both genders. In response to each item on the measure, participants are instructed to indicate their experience with a traumatic event on a 5 -point Likert-type scale $(0=$ never; $4=$ many times). If a participant denotes that she/he has experienced the traumatic event, then he/she is asked to describe her/his appraisal of its effect on a 7-point Likert-type scale $(1=$ extremely positive; $7=$ extremely negative). CTS-S includes two general subscales for cumulative trauma dose: occurrence and frequency of experience, and two appraisal subscales: negative and positive appraisal of events. These four sub-scales may be also generated for each of the trauma types.

The CTS-S has shown adequate internal consistency ( $\alpha=0.85$; Kira et al., 2008, Kira, Fawzi, \& Fawzi, 2013; Kira, Shuwiekh, Rice, Al Ibraheem, \& Aljakoub, 2017). Evidence of the instrument's predictive validity includes cumulative trauma significantly predicting post-traumatic stress disorder $(\mathrm{r}=0.54, p<$ $0.001)$, cumulative trauma-related disorders $(\mathrm{r}=0.24, p<0.001)$, and poor health ( $\mathrm{r}=0.37, p<0.001$; Kira et al., 2008). CTS-S has also shown divergent validity: It was significantly negatively correlated with sociocultural adjustment ( $\mathrm{r}$ $=-0.25, p<0.001)$ and futuristic orientation $(\mathrm{r}=-0.37, p<0.001)$. CTS-S has been used with a variety of clinical and community samples of adults and adolescents from numerous sociocultural groups and has been shown to possess adequate reliability (with an alpha ranging between 0.80 and 0.92 ), good construct validity (e.g., Kira et al., 2008, Kira, Lewandowski, Somers, Yoon, \& Chiodo, 2012; Kira, Smith, Lewandowski, \& Templin, 2010), and validity across different cultural and clinical groups, including American Indians, Mayans, Palestinians, Egyptians, refugees, and torture survivors from 32 countries (e.g., Kira, Ashby, Odenat, \& Lewandowski, 2013; Kira, Fawzi, \& Fawzi, 2013; Kira, Omidy, \& Ashby, 2014; Kira et al., 2010). The measure has been translated into different languages including Arabic, Spanish, Polish, Korean, Turkish, and Nigerian and 
proved to have good psychometric properties in these languages. Test-retest using an independent sample of 35 males with four weeks interval yielded excellent stability coefficients ( 0.995 for cumulative trauma frequency, and 0.997 for cumulative trauma appraisal). The alpha for the main scale of occurrence was 0.89 in current data.

Psychopathology Screening Measure (Kira, Shuwiekh, \& Kucharska, 2017) Adapted GAIN Short Screener (GAIN-SS) (Dennis, Chan, \& Funk, 2006) is a screener that quickly identifies clients (adults and adolescents) who are likely to have mental health disorders, issues with crime/violence, and issues with substance use. The participant is asked to indicate if the behavior (or feeling) happened in the past month (scored 4), or happened in the last 2 - 3 months (scored 3 ), or in the last 3 - 12 months (scored 2), or the last year or more (scored 1), or never happened (scored 0 ). The adapted measure includes a section for psychoticism and dissociation, as well as suicidality. The suicidality with evaluated by a single item that asked if you think about hurting yourself, ending your life or committing suicide. The goal of its adaptation was to include the three basic components of psychopathology: Internalizing, Externalizing and thought disorder (psychoticism) (e.g. Caspi et al., 2014; Laceulle, Volleberge, \& Ormel, 2015). The current adapted measure includes 20 items. Exploratory and Confirmatory Factor Analysis of the adapted measure in different data in Egypt and Poland yielded three factors: Internalizing, Externalizing and psychoticism. Test-retest using an independent sample of 35 males with four weeks interval yielded excellent stability coefficients $(0.970$ for internalizing, 0.908 for externalizing, 915 for the combined externalizing and addiction subscale. The total scale of psychopathology scale has an alpha of 0.89 in current data. We used the suicidality subscale in this measure.

Interfaith Spirituality Scale (25 items) (Kira, Shuwiekh, Al-Huwailah, Zidan, \& Bujold-Bugeaud, 2019): IFS included 25 items that represented five components (and subscales): direct connection with the creating force, asceticism, the unity of existence, meditation, and divine love. Because the unity of existence subscale had low reliability, it was eliminated from the analysis. For each item, each participant was asked to indicate to what extent each statement is true for him/her on a scale from 1 - 4, with (4) Mostly true about me, and (1) Not true about me. The instruction introduced a specific definition of spirituality as "the feeling of a direct relationship with your creator, and your ability to transcend yourself. With 'Creator' means the power that put everything into existence, as you perceive it." The measure and its short form (5 items) were tested on a sample of 490 in Egypt, (Christians, $\mathrm{N}=247$ and Muslims, $\mathrm{N}=243$ ), 58.6\% females, and include three sub-regional groups (Qena, Upper Egypt, $\mathrm{N}=210$ ). Fayoum (Middle Egypt, $\mathrm{N}=184$, and Cairo, $\mathrm{N}=96$ ). Exploratory and confirmatory factor analysis validated its structure and found a second-order unitary construct of IFS. The measure was found to be strictly invariant across religions, genders, ages, and regional groups. IFS, its subscales, and its short form found to have good inter-items and test-retest reliability, Criterion, convergent, divergent, 
predictive and incremental validity. IFS and its subscales were associated with religiosity, higher self-esteem, higher emotional regulation, higher will-to exist-live and survive, and posttraumatic growth. They were negatively associated with PTSD, depression, suicidality, externalizing, thought disorder and psychopathology in general. Internal consistency $\alpha$ for the scale (25 items) was 0.92 . Alpha for direct connection with the creator subscale ( 8 items) was 0.87 , for asceticism Subscale (5 items) was 0.82 , for meditation subscale ( 7 items) was 0.83 , for divine love subscale ( 3 items) alpha was 0.69 and 0.52 for Unity of existence subscale (2 items). Test-retest ( 4 weeks interval between time 1 and time 2 ) on a sample of $(\mathrm{N}=34)$ found to be 0.72 . However, because the unity of existence subscale loaded significantly on only two items and had relatively low reliability, it was suggested that this dimension needed more development and deleted from the analysis.

Religiosity scale is five items that had been used previously in similar populations (e.g., Al-Ibraheem, Kira, Aljakoub, \& Al-Ibraheem, 2017) and proved to have good reliability, stability, and predictive validity. It contains items that measure the consistent practice of religion. It includes also items about congregating with persons from the same religion, reading the religion's Holy Book, and giving to religious charities. The measure had Cronbach' $\alpha=0.70$ in the present study.

Identity Salience Scale (Kira, Templin et al., 2011; Kira, Alawneh, Aboumediene et al., 2011) is a 10-item scale that developed in two studies on 880 Palestinian adolescents. Identity salience, or dormancy, refers to the status of one group's identity in their nested hierarchy, whether it is central or peripheral. It includes questions like "I feel personally threatened by hate crimes committed against myself or the members of my race, religion, culture or ethnic group or another group of my belonging." Another example is "Sometimes I wish to die or kill somebody or myself before my ethnic, or religion or nation or any other group of my belonging harmed, eliminated or subjugated." The response indicates how much he or she disagrees or agrees on a scale from 1 to $7(1=$ entirely disagree; 7 = absolutely agree). Higher scores indicate greater collective identity salience; lower scores highlight more personal identity salience. There are follow-up questions about the relative importance of each group. Exploratory and confirmatory factor analysis found support for two subscales: identity commitment and identity militancy. Internal consistency reliability (alpha) for the measure was 0.80 for adolescents (and 0.81 in another adult Palestinian sample; N-132), with alphas of 0.74 for the Commitment and 0.75 for the Militancy (ready to die for your group) subscales. Test-retest reliability after three weeks was 0.76 . The measure was found to have good predictive validity. Increased personal and collective identity traumas predicted increases in collective identity salience. Increased identity salience predicted an increase in existential annihilation anxiety and mortality salience. In the current analysis, we considered identity commitment as a measure for collective identity salience, and militancy as one of the coping strategies for collective identity trauma of oppression, through different forms of active resis- 
tance and readiness to sacrifice or die for the group. The scale's alpha was 0.88 in current data. Identity salience (commitment) subscale had an alpha of 0.80 , and identity militancy had an alpha of 0.87 in the present data.

\subsection{Data Analysis}

Descriptive statistics (frequency, rate, mean and standard deviation) were used to describe the sample characteristics. A bivariate correlation was used to calculate the strength of relationships between suicidality and other variables. The linear and non-linear (quadratic and cubic) relationships among the predictor variable: cumulative Stressors and Traumas (CST) and the outcome variables: internalizing, externalizing and thought disorder, were examined first using the conventional curve-estimation regression. We used SPSS-IBM 22 in data analysis, at this stage. The chained cusp quantum models were tested employing a cusp catastrophe modeling method to test three models. Cusp catastrophe models involve asymmetry controlling factors (e.g., age) and bifurcation factors (e.g., CST) that contribute to the cusp, or critical shift in behavior, or a dependent variable (e.g., internalizing, externalizing, and thought disorders). We used age as an asymmetry variable and CST as the bifurcation variable to explore the potential Cusp change in the effects of CST on internalizing, externalizing and thought disorders. The three cusp models were used to assess the fit of each of the three cusp models of CST cusp impact across age (asymmetry) and the bifurcating impact of CST on internalizing, externalizing, and thought disorders. The appropriateness of a cusp catastrophe model is evaluated on the basis of its comparison with both linear and cusp models by using an R2 value, the Akaike information criterion (AIC), and the Bayesian information criterion (BIC) statistics (Browne, 2000; Zucchini, 2000). The model with the highest R2 and the lowest AIC and BIC values provided the best fit to the data. Cusp catastrophe analyses were completed using the open-source software R version 3.2.4 (Team R, 2013).

\section{Results}

Correlation results: Suicidality was associated positively with cumulative trauma, personal identity trauma (for example interpersonal violence) (the highest association), followed by collective identity traumas (e.g., discrimination), attachment traumas, secondary traumas, role identity traumas (e.g., failed business), and survival trauma (e.g., car accident or natural disaster) which have the least association. Suicidality was highly associated negatively with spirituality, followed by religiosity and identity salience (commitment). Table 1 presents these associations.

Curve Estimation results: CST was associated with suicidality both linearly $\left(\mathrm{F}=77.54, p<0.000, \mathrm{R}^{2}=0.074\right)$, and non-linearly (the cubic model $)(\mathrm{F}=31.88$, $p<0.000, \mathrm{R}^{2}=0.090$ ), with the non-linear model accounting for more variance. Figure 1 provides the different curves for the linear, quadratic and cubic models for the relation between CTS and suicidality. 
I. Kira et al.

Table 1. Zero-order correlations between the main variables.

\begin{tabular}{|c|c|c|c|c|c|c|c|c|c|c|c|}
\hline & 1 & 2 & 3 & 4 & 5 & 6 & 7 & 8 & 9 & 10 & 11 \\
\hline 1) Suicidality & 1 & & & & & & & & & & \\
\hline 2) Cumulative Trauma & $0.27^{* * *}$ & 1 & & & & & & & & & \\
\hline 3) Religiosity & $-0.47^{\star * *}$ & $-0.16^{\star * *}$ & 1 & & & & & & & & \\
\hline 4) Personal Identity Traumas & $0.29^{\star * *}$ & $0.84^{* * *}$ & $-0.18^{\star * *}$ & 1 & & & & & & & \\
\hline 5) Collective Identity Trauma & $0.25^{* * *}$ & $0.71^{\star * *}$ & $-0.16^{* * *}$ & $0.61^{* * *}$ & 1 & & & & & & \\
\hline 6) Attachment Trauma & $0.23^{* * *}$ & $0.65^{* * *}$ & $-0.15^{\star * *}$ & $0.57^{* * *}$ & $0.51^{* * *}$ & 1 & & & & & \\
\hline 7) Role Identity Trauma & $0.16^{* * *}$ & $0.58^{* * *}$ & $-0.11^{* * *}$ & $0.42^{* * *}$ & $0.31^{\star * *}$ & $0.29^{* * *}$ & 1 & & & & \\
\hline 8) Survival Trauma & $0.11^{\star * \star}$ & $0.71^{\star * \star}$ & -0.01 & $0.48^{\star * *}$ & $0.36^{* * *}$ & $0.33^{* * *}$ & $0.31^{\star * *}$ & 1 & & & \\
\hline 9) Secondary Trauma & $0.20^{\star * *}$ & $0.82^{\star * *}$ & $-0.12^{* * *}$ & $0.58^{* * *}$ & $0.50^{\star * \star}$ & $0.50^{* * \star}$ & $0.38^{\star * *}$ & $0.55^{\star * *}$ & 1 & & \\
\hline 10) Identity Salience & $-0.35^{\star * *}$ & $-0.16^{\star * *}$ & $0.47^{* * *}$ & $-0.18^{\star * *}$ & $-0.13^{* * *}$ & $-0.18^{\star * *}$ & $-0.08^{\star *}$ & -0.06 & $-0.12^{\star * *}$ & 1 & 0. \\
\hline 11) Spirituality & $-0.62^{\star \star \star}$ & $-0.28^{\star * \star}$ & $0.64^{\star * *}$ & $-0.28^{\star * *}$ & $-0.26^{\star \star \star}$ & $-0.28^{\star * *}$ & $-0.17^{\star * *}$ & $-0.12^{\star * *}$ & $-0.21^{\star * *}$ & $0.47^{* * *}$ & 1 \\
\hline
\end{tabular}

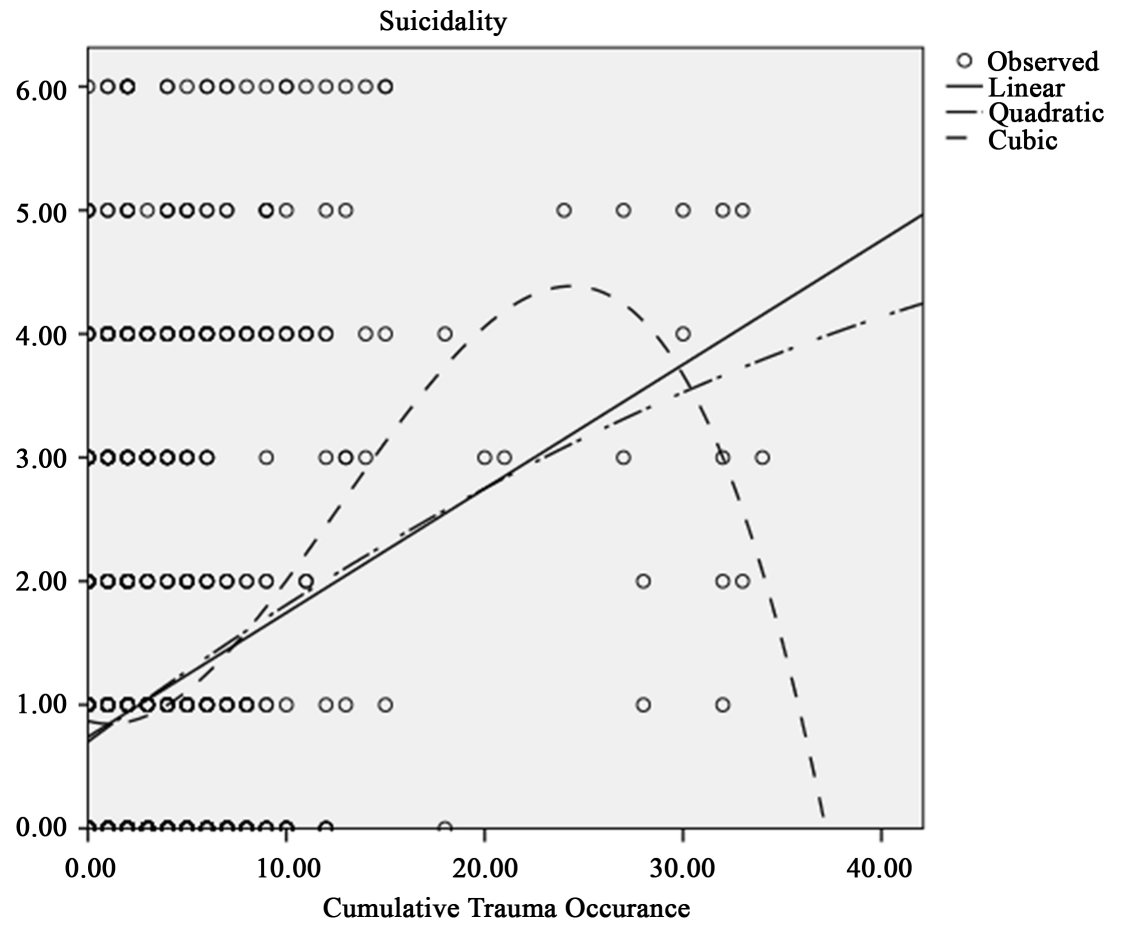

Figure 1. Curve estimation regression for linear, quadratic and cubic models for the relationship between cumulative stressors and traumas and suicidality.

Cusp results: The results of polynomial regression cusp catastrophe models showed that CST was a significant bifurcation factor for suicide. Age was a significant asymmetry controlling factor as well. Polynomial factors (i.e., $\mathrm{z}$ values) were significant, indicating that the change in suicide can be explained by the cusp model with the combination of the significant bifurcation and asymmetry controlling factors. The $\mathrm{R}^{2}$ in the Cusp model, $\mathrm{R}^{2}=0.762$ for suicide, accounting for much higher variance than the linear model. Results indicated that the Cusp 
model for suicide $\left(\mathrm{R}^{2}=0.762 ; A I C=1094.744 ; B I C=1132.12\right)$ provided a superior fit to the data than could the linear model $\left(\mathrm{R}^{2}=0.045 ; A I C=2342.638 ; B I C\right.$ $=2370.67)$. These results suggest that the linear model greatly underestimates the fit of the data to the model, accounting for much less than of the variance explained by a Cusp catastrophe model. Specifically, the Cusp catastrophe model is much more accurate $\left(\mathrm{R}^{2}=0.762\right)$ bettering the corresponding linear model $\left(\mathrm{R}^{2}\right.$ $=0.045)$. The $B I C$ and $A I C$ values greatly lower in the Cusp model than the linear model. Table 2 summarizes these findings. Figure 2 illustrates the three dimensions of the Cusp model for the impact of cumulative stressors and trauma as bifurcation factor and age as asymmetrical factors and suicidality as an outcome factor.

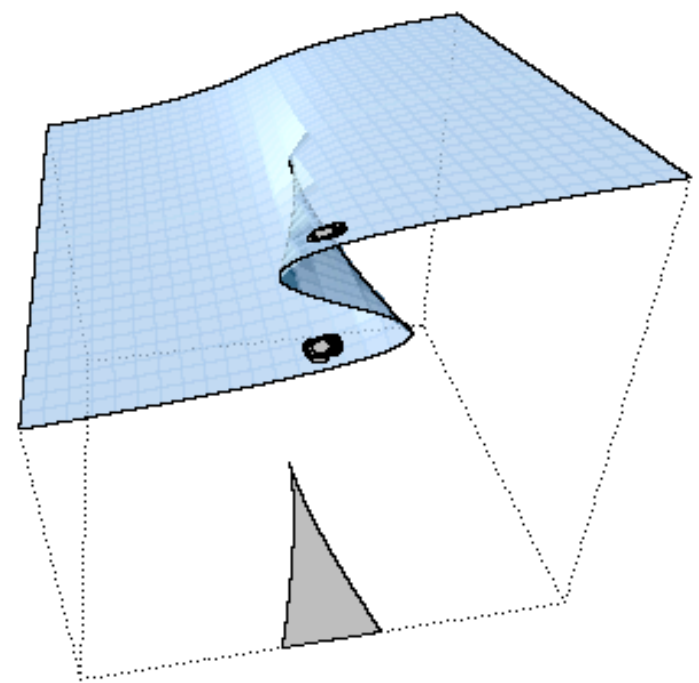

Figure 2. Three dimensional for Cusp catastrophe analyses for the CST as a bifurcation factor (vertical axis) and age as an asymmetrical factor (horizontal axis) to Suicide as Cusp outcome.

Table 2. Chained cusp catastrophe of the impact of cumulative stressors and traumas on suicide.

\begin{tabular}{cccc}
\hline Quantum Change Variable & \multicolumn{3}{c}{ Z Values } \\
\hline Outcome: Suicide & & \\
Asymmetry & & & \\
& Intercept & 0.749 & \\
& Age & $-3.682^{* * *}$ & \\
Bifurcation & & & \\
& Intercept & $31.889^{* * *}$ & BIC \\
& CST & 0.626 & 1132.12 \\
Model fit & $R^{2}$ & $A I C$ & 2370.67 \\
Cusp & 0.762 & 1094.744 & 2342.638 \\
Linear & 0.045 & & \\
\hline
\end{tabular}




\section{Discussion}

These results provided evidence of the superiority of a Cusp catastrophe model over a regression linear model when investigating CST as a bifurcation control factor and a nonlinear predictor of suicidality. Results confirmed the non-linear threshold model of the relation between cumulative stressors and traumas (CTS) and suicidality. This is the first study that confirmed the dynamic non-linear model of suicidality. We assume that the control parameters of a person's characteristics will determine the threshold of tolerance before the buffer breaks and suicidality erupts. We assumed that the age may, at least partially, function to determine person's characteristics at this age or time point and play the role as asymmetrical control factor in the Cusp model. While all different trauma types were associated with suicidality with different intensities, personal identity trauma was the strongest and survival trauma was the weakest. Using single trauma or the event the directly preceded suicidality can be misleading. This preceded stressor can be the last straw that broke the camel's back. The cumulative and proliferation dynamics of trauma are more powerful bifurcation control factor in these non-linear dynamics. In addition to the cumulative dynamics, trauma proliferation (Kira et al., 2018) can be other dynamics related to the cumulative impact. There is evidence that attachment and childhood traumas that may happen early-on proliferate to other subsequent traumas later-in-life. The same was found for collective identity traumas such as discrimination and oppression that start with adolescence (Kira et al., 2018). The cumulative impact and the proliferation of early and identity traumas to subsequent traumas are the strongest dynamics that impact suicidality non-linearly (Kira et al., 2019).

Our analysis confirmed that interfaith spirituality (meaning-making) is the strongest protective factor, followed by religiosity and identity salience. The role of religiosity, as a buffer against suicidality, has been documented in the literature (for meta-analysis on the role of religiosity see, Wu, Wang, \& Jia, 2015). However, the role of identity and mostly of spirituality as buffers and in treating suicidality is relatively underutilized in clinical intervention and prevention. The intervention and prevention programs that focused on enhancing different components of spirituality and meaning-making should work. Working with religious leaders to fight suicidality among their followers can be potentially effective. Interventions that are focused on strengthening identity commitment and belonging of persons at risk should minimize or prevent the sudden emergence of suicidality (e.g., Kira, Ashby, Omidy, \& Lewandowski, 2015; Kira \& Tummala-Narra, 2015).

The current study, while provides significant potential contributions to understanding the dynamics leading to suicidality has several limitations. One of the limitations was using age as a function of the person's characteristics at a certain point of time as the asymmetrical factor in the Cusp dynamics. Age can provide limited representation of person's characteristics. Why did age enter as asymmetry variable? A myriad of alternative asymmetrical factors may be possi- 
ble. Another limitation is that the study used mostly convenient samples that may have limited and biased representation. We recommend more studies that use more representative samples. Another limitation is that the measures we used are based on participants' self-reports, which could be subject to under- or over-reporting of events due to current symptoms, embarrassment, shame, or social desirability. Another limitation is that we utilized a cross-sectional design in testing our model, cross-sectional data can produce biased estimates (Maxwell \& Cole, 2007). Future studies may use longitudinal studies if feasible to retest the proposed model. Also, a cross-sectional design does not provide deterministic hard science models. Only probabilistic relationships can be drawn from the results. Deterministic causal relationships can be obtained using experimental designs if feasible.

\section{Conflicts of Interest}

The authors declare no conflicts of interest regarding the publication of this paper.

\section{References}

Adam, K. S., Sheldon-Keller, A. E., \& West, M. (1996). Attachment Organization and History of Suicidal Behavior in Clinical Adolescents. Journal of Consulting and Clinical Psychology, 64, 264-272. https://doi.org/10.1037/0022-006X.64.2.264

Al-Ibraheem, B., Kira, I., Aljakoub, J., \& Al-Ibraheem, A. (2017). The Health Effect of the Syrian Conflict on IDPs and Refugees. Peace and Conflict: Journal of Peace Psychology, 23, 140-152. https://doi.org/10.1037/pac0000247

Blosnich, J. R., Brown, G. R., Shipherd, J. C., Kauth, M., Piegari, R. I., \& Bossarte, R. M. (2013). Prevalence of Gender Identity Disorder and Suicide Risk among Transgender Veterans Utilizing Veterans Health Administration Care. American Journal of Public Health, 103, e27-e32. https://doi.org/10.2105/AJPH.2013.301507

Bonelli, R. M., \& Koenig, H. G. (2013). Mental Disorders, Religion and Spirituality 1990 to 2010: A Systematic Evidence-Based Review. Journal of Religion and Health, 52, 657-673. https://doi.org/10.1007/s10943-013-9691-4

Brent, D. A., Baugher, M., Bridge, J., Chen, T., \& Chiappetta, L. (1999). Age- and Sex-Related Risk Factors for Adolescent Suicide. Journal of the American Academy of Child \& Adolescent Psychiatry, 38, 1497-1505. https://doi.org/10.1097/00004583-199912000-00010

Browne, M. W. (2000). Cross-Validation Methods. Journal of Mathematical Psychology, $44,108-132$.

Caspi, A., Houts, R. M., Belsky, D. W., Goldman-Mellor, S. J., Harrington, H., Israel, S., Moffitt, T. E. et al. (2014). The p Factor: One General Psychopathology Factor in the Structure of Psychiatric Disorders? Clinical Psychological Science, 2, 119-137. https://doi.org/10.1177/2167702613497473

Chandler, M. J., Lalonde, C. E., Sokol, B. W., Hallett, D., \& Marcia, J. E. (2003). Personal Persistence, Identity Development, and Suicide: A Study of Native and Non-Native North American Adolescents. Monographs of the Society for Research in Child Development, 68, 1-138.

Chen, X., \& Chen, D. (2015). Cusp Catastrophe Modeling in Medical and Health Re- 
search. In D. Chen, \& J. Wilson (Eds.), Innovative Statistical Methods for Public Health Data (pp. 265-290). Berlin: Springer International Publishing. https://doi.org/10.1007/978-3-319-18536-1_12

Clements-Nolle, K., Marx, R., \& Katz, M. (2006). Attempted Suicide among Transgender Persons: The Influence of Gender-Based Discrimination and Victimization. Journal of Homosexuality, 51, 53-69. https://doi.org/10.1300/J082v51n03_04

Cloitre, M., Stolbach, B. C., Herman, J. L., Kolk, B. V. D., Pynoos, R., Wang, J., \& Petkova, E. (2009). A Developmental Approach to Complex PTSD: Childhood and Adult Cumulative Trauma as Predictors of Symptom Complexity. Journal of Traumatic Stress, 22, 399-408. https://doi.org/10.1002/jts.20444

Colucci, E., \& Martin, G. (2008). Religion and Spirituality along the Suicidal Path. Suicide and Life-Threatening Behavior, 38, 229-244. https://doi.org/10.1521/suli.2008.38.2.229

de Wilde, E. J., Kienhorst, I. C., Diekstra, R. F., \& Wolters, W. H. (1992). The Relationship between Adolescent Suicidal Behavior and Life Events in Childhood and Adolescence. American Journal of Psychiatry, 149, 45-51.

https://doi.org/10.1176/ajp.149.1.45

Dennis, M. L., Chan, Y. F., \& Funk, R. R. (2006). Development and Validation of the GAIN Short Screener (GSS) for Internalizing, Externalizing and Substance Use Disorders and Crime/Violence Problems among Adolescents and Adults. The American Journal on Addictions, 15, s80-s91. https://doi.org/10.1080/10550490601006055

Dervic, K., Oquendo, M. A., Grunebaum, M. F., Ellis, S., Burke, A. K., \& Mann, J. J. (2004). Religious Affiliation and Suicide Attempt. American Journal of Psychiatry, 161, 2303-2308. https://doi.org/10.1176/appi.ajp.161.12.2303

Devries, K. M., Mak, J. Y., Child, J. C., Falder, G., Bacchus, L. J., Astbury, J., \& Watts, C. H. (2014). Childhood Sexual Abuse and Suicidal Behavior: A Meta-Analysis. Pediatrics, 133, e1331-e1344. https://doi.org/10.1542/peds.2013-2166

Ehlers, C. L. (1995). Chaos and Complexity: Can It Help Us to Understand Mood and Behavior? Archives of General Psychiatry, 52, 960-964. https://doi.org/10.1001/archpsyc.1995.03950230074010

Flay, B. R. (1978). Catastrophe Theory in Social Psychology: Some Applications to Attitudes and Social Behavior. Behavioral Science, 23, 335-350. https://doi.org/10.1002/bs.3830230404

Gilmore, R. (1993). Catastrophe Theory for Scientists and Engineers. North Chelmsford, MA: Courier Corporation.

Guastello, S. J., \& Liebovitch, L. S. (2009). Introduction to Nonlinear Dynamics and Complexity. In S. J. Guastello, M. Koopmans, \& D. Pincus (Eds.), Chaos and Complexity in Psychology: The Theory of Nonlinear Dynamical Systems (pp. 1-40). New York: Cambridge University Press. https://doi.org/10.1017/CBO9781139058544.002

Joiner, T. E. (2005). Why People Die by Suicide. Cambridge, MA: Harvard University Press.

Kira, I. (2001). Taxonomy of Trauma and Trauma Assessment. Traumatology, 2, 1-14. https://doi.org/10.1177/153476560100700202

Kira, I. (2010). Etiology and Treatments of Post-Cumulative Traumatic Stress Disorders in Different Cultures. Traumatology: An International Journal, 16, 128-141. https://doi.org/10.1177/1534765610365914

Kira, I. (2019). Toward an Integrative Theory of Self-Identity and Identity Stressors and 
Traumas and Its Mental Health Dynamic. Psychology, 10, 385-410. https://doi.org/10.4236/psych.2019.104027

Kira, I. A. (2017). A Critical Outlook at Torture Definition, Structure, Dynamics, and Interventions. Peace and Conflict: Journal of Peace Psychology, 23, 328. https://doi.org/10.1037/pac0000243

Kira, I. A., \& Tummala-Narra, P. (2015). Psychotherapy with Refugees: Emerging Paradigm. Journal of Loss and Trauma, 20, 449-467. https://doi.org/10.1080/15325024.2014.949145

Kira, I. A., \& Wroble, N. H. (2016). Trauma: Stress, Coping, and Emerging Treatment Models. In M. M. Amer, \& G. H. Awad (Eds.), Handbook of Arab American Psychology (pp. 188-205). New York: Routledge.

Kira, I. A., Omidy, A. Z., \& Ashby, J. S. (2014). Cumulative Trauma, Appraisal, and Coping in Palestinian and American Indian Adults: Two Cross-Cultural Studies. Traumatology: An International Journal, 20, 119-133. https://doi.org/10.1037/h0099397

Kira, I. A., Shuwiekh, H., \& Kucharska, J. (2017). Screening for Psychopathology Using the Three Factors Model of the Structure of Psychopathology: A Modified Form of GAIN Short Screener. Psychology, 8, 2410-2427.

https://doi.org/10.4236/psych.2017.814152

Kira, I. A., Shuwiekh, H., Kucharska, J., Fawzi, M., Ashby, J. S., Omidy, A. Z., Abou-Mediene, S., \& Lewandowski, L. (2018). Trauma Proliferation and Stress Generation (TPSG) Dynamics and Their Implications for Clinical Science. American Journal of Orthopsychiatry, 88, 582-596. https://doi.org/10.1037/ort0000304

Kira, I., Alawneh, A. N., Aboumediane, S., Mohanesh, J., Ozkan, B., \& Alamia, H. (2011). Identity Salience and Its Dynamics in Palestinians Adolescents. Psychology, 2, 781-791. https://doi.org/10.4236/psych.2011.28120

Kira, I., Ashby, J. S., Lewandowski, L., Alawneh, A. N., Mohanesh, J., \& Odenat, L. (2013). Advances in Continuous Traumatic Stress Theory: Traumatogenic Dynamics and Consequences of Intergroup Conflict: The Palestinian Adolescents Case. Psychology, 4, 396-409. https://doi.org/10.4236/psych.2013.44057

Kira, I., Ashby, J. S., Odenat, L., \& Lewandowski, L. (2013). The Mental Health Effects of Torture Trauma and Its Severity: A Replication and Extension. Psychology, 4, 472-482. https://doi.org/10.4236/psych.2013.45067

Kira, I., Ashby, J. S., Omidy, A. Z., \& Lewandowski, L. (2015). Current, Continuous, and Cumulative Trauma-Focused Cognitive Behavior Therapy: A New Model for Trauma Counseling. Journal of Mental Health Counseling, 37, 323-340.

https://doi.org/10.17744/mehc.37.4.04

Kira, I., Fawzi, M., \& Fawzi, M. (2013). The Dynamics of Cumulative Trauma and Trauma Types in Adult Patients with Psychiatric Disorders: Two Cross-Cultural Studies. Traumatology: An International Journal, 19, 179-195. https://doi.org/10.1177/1534765612459892

Kira, I., Fawzi, M., Shuwiekh, H., Lewandowski, L., Ashby, J., \& Al Ibraheem, B. (2019). Do Adding Attachment, Oppression, Cumulative and Proliferation Trauma Dynamics to PTSD Criterion "A" Improve Its Predictive Validity: Toward a Paradigm Shift? Current Psychology. https://doi.org/10.1007/s12144-019-00206-Z

Kira, I., Lewandowski, L., Chiodo, L., \& Ibrahim, A. (2014). Advances in Systemic Trauma Theory: Traumatogenic Dynamics and Consequences of Backlash as a Multi-Systemic Trauma on Iraqi Refugee Muslim Adolescents. Psychology, 5, 389-412. https://doi.org/10.4236/psych.2014.55050 
Kira, I., Lewandowski, L., Somers, C., Yoon, J., \& Chiodo, L. (2012). PTSD, Trauma Types, Cumulative Trauma, and IQ: The Case of African American and Iraqi Refugee Adolescents. Psychological Trauma: Theory, Research, Practice, and Policy, 4, 128-139. https://doi.org/10.1037/a0022121

Kira, I., Lewandowski, L., Templin, T., Ramaswamy, V., Ozkan, B., \& Mohanesh, J. (2008). Measuring Cumulative Trauma Dose, Types and Profiles Using a Development-Based Taxonomy of Trauma. Traumatology: International Journal, 14, 62-87. https://doi.org/10.1177/1534765608319324

Kira, I., Lewandowski, L., Templin, T., Ramaswamy, V., Ozkan, B., \& Mohanesh, J. (2010). The Effects of Perceived Discrimination and Backlash on Iraqi Refugees' Physical and Mental Health. Journal of Muslim Mental Health, 5, 59-81. https://doi.org/10.1080/15564901003622110

Kira, I., Shuwiekh, H., Al Ibraheem, B., \& Aljakoub, J. (2018). Appraisals and Emotion Regulation Mediate the Effects of Identity Salience and Cumulative Stressors and Traumas, on PTG and Mental Health: The Case of Syrian's IDPs and Refugees. Self and Identity: The Journal of the International Society for Self and Identity, 18, 284-305. https://doi.org/10.1080/15298868.2018.1451361

Kira, I., Shuwiekh, H., Al-Huwailah, A. H., Zidan, T., \& Bujold-Bugeaud, M. (2019). Measuring Interfaith Spirituality: Initial Validation and Psychometrics. Psychology of Religion and Spirituality. https://doi.org/10.1037/rel0000242

Kira, I., Shuwiekh, H., Rice, K., Al Ibraheem, B., \& Aljakoub, J. (2017). A Threatened Identity: The Mental Health Status of Syrian Refugees in Egypt and Its Etiology. Identity: An International Journal of Theory and Research, 3, 176-190. https://doi.org/10.1080/15283488.2017.1340163

Kira, I., Smith, I., Lewandowski, L., \& Templin, T. (2010). The Effects of Perceived Gender Discrimination on Refugee Torture Survivors: A Cross-Cultural Traumatology Perspective. Journal of the American Psychiatric Nurses Association, 16, 299-306. https://doi.org/10.1177/1078390310384401

Klonsky, E. D., \& May, A. M. (2015). The Three-Step Theory (3ST): A New Theory of Suicide Rooted in the "Ideation-to-Action" Framework. International Journal of Cognitive Therapy, 8, 114-129. https://doi.org/10.1521/ijct.2015.8.2.114

Laceulle, O. M., Vollebergh, W. A. M., \& Ormel, J. (2015). The Structure of Psychopathology in Adolescence: Replication of a General Psychopathology Factor in the TRAILS Study. Clinical Psychological Science, 3, 850-860.

https://doi.org/10.1177/2167702614560750

Leyro, T. M., Zvolensky, M. J., \& Bernstein, A. (2010). Distress Tolerance and Psychopathological Symptoms and Disorders: A Review of the Empirical Literature among Adults. Psychological Bulletin, 136, 576. https://doi.org/10.1037/a0019712

Martin, C. G., Cromer, L. D., DePrince, A. P., \& Freyd, J. J. (2013). The Role of Cumulative Trauma, Betrayal, and Appraisals in Understanding Trauma Symptomatology. Psychological Trauma: Theory, Research, Practice, and Policy, 5, 110-118. https://doi.org/10.1037/a0025686

Maxwell, S. E., \& Cole, D. A. (2007). Bias in Cross-Sectional Analyses of Longitudinal Mediation. Psychological Methods, 12, 23-44. https://doi.org/10.1037/1082-989X.12.1.23

O’Connor, R. C., \& Kirtley, O. J. (2018). The Integrated Motivational-Volitional Model of Suicidal Behaviour. Philosophical Transactions of the Royal Society B: Biological Sciences, 373, 20170268. https://doi.org/10.1098/rstb.2017.0268 
Oldfield, J., Humphrey, N., \& Hebron, J. (2015). Cumulative Risk Effects for the Development of Behaviour Difficulties in Children and Adolescents with Special Educational Needs and Disabilities. Research in Developmental Disabilities, 41, 66-75. https://doi.org/10.1016/j.ridd.2015.05.010

Orbach, I., \& Iohan-Barak, M. (2009). Psychopathology and Risk Factors for Suicide in the Young: Theoretical and Empirical. In D. Wasserman, \& C. Wasserman (Eds.), $O_{X}$ ford Textbook of Suicidology and Suicide Prevention: A Global Perspective (pp. 633-642). Oxford: Oxford University Press. https://doi.org/10.1093/med/9780198570059.003.0087

Post, R. M., Weiss, S. R. B., \& Smith, M. A. (1995). Sensitization and Kindling: Implications for the Evolving Neural Substrates of Post-Traumatic Stress Disorder. In M. J. Friedman, D. S. Charney, \& A. Y. Deutch (Eds.), Neurobiological and Clinical Consequences of Stress: From Normal Adaptation to Post-Traumatic Stress Disorder (pp. 203-224). Philadelphia, PA: Lippincott Williams \& Wilkins.

Rasic, D., Robinson, J. A., Bolton, J., Bienvenu, O. J., \& Sareen, J. (2011). Longitudinal Relationships of Religious Worship Attendance and Spirituality with Major Depression, Anxiety Disorders, and Suicidal Ideation and Attempts: Findings from the Baltimore Epidemiologic Catchment Area Study. Journal of Psychiatric Research, 45, 848-854. https://doi.org/10.1016/j.jpsychires.2010.11.014

Rudd, M. D. (2006). Fluid Vulnerability Theory: A Cognitive Approach to Understanding the Process of Acute and Chronic Suicide Risk. In T. E. Ellis (Ed.), Cognition and Suicide: Theory, Research, and Therapy (pp. 355-368). Washington DC: American Psychological Association. https://doi.org/10.1037/11377-016

Schiepek, G., Fartacek, C., Sturm, J., Kralovec, K., Fartacek, R., \& Plöderl, M. (2011). Nonlinear Dynamics: Theoretical Perspectives and Application to Suicidology. Suicide and Life: Threatening Behavior, 41, 661-675. https://doi.org/10.1111/j.1943-278X.2011.00062.x

Stein, M. B., Jang, K. L., Taylor, S., Vernon, P. A., \& Livesley, W. J. (2002). Genetic and Environmental Influences on Trauma Exposure and Posttraumatic Stress Disorder Symptoms: A Twin Study. American Journal of Psychiatry, 159, 1675-1681. https://doi.org/10.1176/appi.ajp.159.10.1675

The Team R (2013). R Development Core Team. R: A Language and Environment for Statistical Computing, 55, 275-286.

Thom, R. (1975). Structural Stability and Morphogenesis. New York: Benjamin-AddisonWesley.

Van Orden, K. A., Witte, T. K., Cukrowicz, K. C., Braithwaite, S. R., Selby, E. A., \& Joiner, T. E. Jr. (2010). The Interpersonal Theory of Suicide. Psychological Review, 117, 575-600. https://doi.org/10.1037/a0018697

Walker, R. L., Wingate, L. R., Obasi, E. M., \& Joiner, T. E. Jr. (2008). An Empirical Investigation of Acculturative Stress and Ethnic Identity as Moderators for Depression and Suicidal Ideation in College Students. Cultural Diversity and Ethnic Minority Psychology, 14, 75-82. https://doi.org/10.1037/1099-9809.14.1.75

World Health Organization (2017). Suicide. Fact Sheet. http://www.who.int/mediacentre/factsheets/fs398/en

Wu, A., Wang, J. Y., \& Jia, C. X. (2015). Religion and Completed Suicide: A Meta-Analysis. PLOS ONE, 10, e0131715.

https://doi.org/10.1371/journal.pone.0131715

Zeeman, E. C. (1976). Catastrophe Theory. Scientific American, 234, 65-83. 
I. Kira et al.

https://doi.org/10.1038/scientificamerican0476-65

Zucchini, W. (2000). An Introduction to Model Selection. Journal of Mathematical Psychology, 44, 41-61. 